\title{
Factors Affecting Delivery Health Service Satisfaction of Women and Fear of COVID-19: Implications for Maternal and Child Health in Pakistan
}

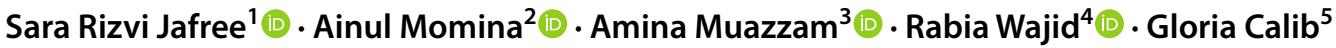

Accepted: 19 April 2021 / Published online: 26 April 2021

(c) The Author(s), under exclusive licence to Springer Science+Business Media, LLC, part of Springer Nature 2021

\begin{abstract}
Objective High maternal and neonatal mortality rates in developing regions like Pakistan are linked to low rates of institutional deliveries. One way to improve rates of institutional deliveries is through improving institutional delivery service satisfaction in women. The aim of this research is to identify which factors influence delivery service satisfaction during the period of COVID-19 and which socio-demographic characteristics of women are associated with greater fear of catching COVID-19 during institutional deliveries.

Methods A total of 190 women who had given birth between May to June, 2020, were sampled from two private and two public sector hospitals in Lahore, Pakistan. A standardized tool was modified for use and a combination of descriptive statistics and multivariate regression was applied.

Results The results reveal that a majority of women, at 74.7\%, are afraid of contracting COVID-19; specifically, women delivering at public hospitals, those who are illiterate or semi-literate, with more than four children, with low household income, and who are unemployed. Regression models are used to identify factors related to higher satisfaction, including the following: (i) pre-delivery care (explanatory power of $R^{2}=0.651$ ); (ii) during delivery care $\left(R^{2}=0.716\right.$ ); (iii) after delivery care for women $\left(\mathrm{R}^{2}=0.525\right)$; and (iv) after delivery care for newborn $\left(\mathrm{R}^{2}=0.780\right)$. The main areas which influence satisfaction include the following: service quality of staff and administration; maintenance of hygiene and sanitation; involvement in decision-making; provision of necessary information; and advice for breastfeeding, immunization and family planning. Conclusions for Practice Based on our findings, we recommend improved regulation of delivery services in both public and private hospitals and increased protection for disadvantaged women groups to maintain service quality during the pandemic.
\end{abstract}

Keywords Delivery services $\cdot$ Institutional deliveries $\cdot$ Pakistan $\cdot$ COVID-19 $\cdot$ Maternal and neonatal health

Sara Rizvi Jafree

sarajafree@fccollege.edu.pk

http://www.fccollege.edu.pk/member/dr-sara-rizvi-jafree/

Ainul Momina

ainmomina@gmail.com

Amina Muazzam

amina_muazzam@hotmail.com

Rabia Wajid

dr.rabia.adnan@gmail.com

Gloria Calib

gloriacalib@fccollege.edu.pk
1 Department of Sociology, Forman Christian College University, Ferozepur Road, Lahore 54600, Pakistan

2 Institute of Public Health, King Edward Medical University, Lahore, Pakistan

3 Lahore College Women University, Lahore, Pakistan

4 Lady Willingdon Hospital and King Edward Medical University, Lahore, Pakistan

5 Forman Christian College, Chartered University, Dhaka 1209, Bangladesh 


\section{Significance}

What is known about this subject. High maternal and neonatal mortality in developing countries, and Pakistan, is associated with low levels of institutional deliveries. Since the coronavirus pandemic began, there has been limited research on identifying factors affecting institutional delivery satisfaction in mothers.

What this study adds. Satisfaction of mothers with institutional deliveries is associated with service quality, maintenance of hygiene and sanitation, involvement in decision-making, and advice for breastfeeding, immunization and family planning. Women from disadvantaged backgrounds have greater fear of contracting COVID-19. Improved regulation of delivery services in both public and private hospitals and increased protection for disadvantaged women groups can improve commitment to institutional deliveries and further support maternal and child health indicators.

\section{Background}

The maternal mortality rate, neonatal mortality rate, and under five-year old child mortality rate for Pakistan are unsatisfactory (Alimohamadi et al., 2019; Habib et al., 2019). One of the reasons identified for the high mortality rates in developing regions is low levels of institutional deliveries with skilled providers (Randive et al., 2014; Yoseph et al., 2020). The most recent nationwide data from the Pakistan Demographic Health Survey reports that 34\% of women do not opt for institutions for safe deliveries (National Institute of Population Studies, 2017-18). The reasons for not choosing institutional deliveries in the country include the following: (i) preference for home deliveries and traditional midwives of the community (Sarfraz \& Hamid, 2014); (ii) fear that institutional staff will force unnecessary C-sections (Nazir, 2015); (iii) inability to access or pay for institutional deliveries (Jafree et al., 2018); and (iv) lack of permission from husband and in-laws (Agha, 2011). During the coronavirus pandemic, additional fear exists that many women might revert to home deliveries if they hear about lack of safety and preventive precautions being practiced in hospitals and health centers.

The fear of home deliveries is that, in the event of an emergency or complications, there would be no time, or less time, to move the women concerned to an institutional setting with the required resources, equipment (Khan et al., 2009), and specialized assistance (Tura et al., 2013). In addition, home deliveries are not known for developing or providing the complete set of services for post-partum care for women and newborn care, such as advice regarding feeding, immunization, family planning, and the physical recovery of women (Lancet Neonatal Survival Steering Team, 2005; World Health Organization, 2010). Research suggests that fewer than $50 \%$ of Pakistani women get postpartum and newborn care (National Institute of Population Studies, 2013). One of the major reasons for lower delivery service care, as discussed above, includes lower institutional deliveries, but also a lack of training of healthcare providers at hospitals in developing countries (Simkhada et al., 2008). In developing regions, healthcare providers are not held accountable for their services to women and the newborn (Mathole et al., 2004), with research also suggesting that providers may exhibit negative attitudes and even abuse (Mousa \& Turingan, 2019). One means of improving resistance to institutional deliveries is to improve the services of care for women who opt for deliver at institutions (Colombara et al., 2016). Consequently, delivery satisfaction in women would improve word of mouth promotion for institutional deliveries and build trust for institutional healthcare providers and staff (Khowaja et al., 2018).

Both the public and private hospitals of Punjab are regulated by the provincial regulatory authority, the Punjab Healthcare Commission (PHC), which is independent in its operations. The PHC is mandated to ensure that all healthcare establishments adhere to the Minimum Service Delivery Standards (MSDS) while offering maternal and child health services (Punjab Healthcare Commission, 2020). The MSDS have been developed by the PHC and comprise a set of indicators that cover the entire spectrum of healthcare service delivery and care services for obstetric patients, including clinical and managerial aspects for maternal health and health of the newborn.

\section{Study Aim}

One way to improve rates of institutional deliveries is by improving the experience of institutional delivery and service satisfaction in women. In a traditional society like Pakistan, with availability of home delivery services by local midwives, there is concern that during the pandemic many women may revert to home deliveries, due to fears of contracting COVID-19 from unsafe institutions. In this way, the main objective of the current study is to: (i) identify demographic variables associated with fear of contracting COVID-19 during institutional deliveries; and (ii) ascertain factors for delivery service satisfaction in women opting for institutional deliveries during coronavirus pandemic. This is specifically with respect to (a) pre-delivery care, (b) care during delivery, and (c) post-delivery care for women and their newborn. 


\section{Methods}

Ethics approval for this study was given by the Institutional Review Board of Forman Christian College University. All participants consented to participate in this study by completing a consent form prior to taking the survey. No names were asked from participants, with all confidentiality and anonymity being maintained. Additionally, no hospital names were reported due to a lack of permission. Free counseling services were provided to participants by a trained clinical psychologist, if needed, due to the sensitive nature of some of the subject enquired.

\section{Sampling Selection Criteria}

Only women who had delivered at public or private hospitals in Lahore during the COVID-19 pandemic from February 2020 , to June 2020, were sampled. Both public and private hospitals from Category-I Group (Punjab Healthcare Commission, 2020) were considered eligible for sampling, in order to provide homogeneity for data analysis. Currently Lahore, the capital city of Punjab, has a population of 11.2 million people. Category 1 hospitals also commonly cater to populations from peripheral areas that are deprived of adequate health services. There is a total of 36 such hospitals in the city (14 public hospitals and 22 private hospitals). Category-I hospitals are defined as hospitals with at least 50 in-patient beds that provide Basic Emergency Obstetric and Newborn Care (BEmONC) and Comprehensive Emergency Obstetric and Newborn care (CEmONC). BEmONC comprises of the following services: (i) assisted vaginal delivery; (ii) administration of parenteral antibiotics, parenteral anticonvulsants, and parenteral uterotonics; (iii) removal of retained products (manual vacuum aspiration) and manual removal of the placenta; and (iv) basic newborn resuscitation care. CEmONC services include the following: (i) all BEmONC services; (ii) surgical procedures and blood transfusion; and (iii) care services for sick and low birth weight newborn babies.

\section{Survey}

In the study, we use a cross-sectional survey which can be extremely useful for future pandemics and preparations. The survey (Appendix A) is comprised of 39 questions from a standardized tool used by the UK National Health Services (NHS) Survey 2017 (Henderson \& Redshaw, 2017). The scale covers the following domains: (1) Registration and admission services; (2) Birthing and delivery services; and
(3) Post-delivery services. A number of modifications for regional relevancy have been made and questions related to COVID-19 have been added to the survey. Likert scale items range from 1-5 ('Not at all', 'Not really', 'Somewhat', 'Very much', 'All the time'). The Cronbach alpha results show high internal validity of the survey: (i) Pre-delivery care is measured by six items, and has a Cronbach alpha of 0.870; (ii) Care during delivery is measured by 12 items, and has a Cronbach alpha of 0.955 ; and (iii) Care after birth is measured by seven items, and has a Cronbach alpha of 0.870 . The survey was translated into Urdu, the local language, by the first three authors, who are fluent in both languages (Urdu and English).

\section{Data Collection}

The second and fourth authors are medical doctors currently working in Lahore. The first, third and fifth authors are public health researchers. All authors used their network to gain permission for data collection. Finally, permission was granted by two public sector and two private sector hospitals. Data was collected between 15 May to 13 June, 2020 , by the first four authors, through the face-to-face method of data collection. If the participant was illiterate, semi-literate, or busy with a newly-born infant, the data collector assisted in the reading of questions and survey completion. The women were asked permission to participate in the study and, if they were not alone, they were asked to indicate a suitable time for the data collector to return for survey. The respondents were informed of the research objectives by way of an informed cover letter and were made aware of the option to withdraw at any time while filling out the survey. No incentives were provided for participation.

Data collectors adorned PPE kit while collecting data and, if the woman respondent was not wearing a mask, they were provided one, to ensure the safety of both interviewer and interviewee. On average the sampled public sector hospitals have 50-70 women delivering daily and the private hospitals have 10-15 women delivering daily. The four data collectors spent one month collecting data from each hospital, respectively, and were able to spend two four-hour sessions a day on average requesting interviews from a self-assigned daily target of 10 women a day. In total 100 women were sampled from the two public sector hospitals and 90 women were sampled from the private hospitals. The response was low, at $15.8 \%$, with only 190 women being sampled, despite requests from 1200 women who had delivered. We were unable to continue sampling due to the revocation of permission to continue collecting data from the hospitals due to increased protocols for COVID-19 safety. 
Table 1 Socio-demographics of women respondents and fear of catching COVID-19 due to institutional deliveries with chi square association

\begin{tabular}{|c|c|c|c|}
\hline Variable & $\begin{array}{l}f(\%) \\
\mathrm{N}=190\end{array}$ & $\begin{array}{l}\text { Afraid of catching } \\
\text { COVID-19 } \\
n=142\end{array}$ & $\chi^{2}$ (p-value) \\
\hline \multicolumn{4}{|l|}{ Age } \\
\hline $20-29$ & $102(53.7 \%)$ & $69(54.3 \%)$ & $4.67(0.792)$ \\
\hline $30-39$ & $77(40.5 \%)$ & $52(40.9 \%)$ & \\
\hline $40-49$ & $11(5.8 \%)$ & $06(4.8 \%)$ & \\
\hline \multicolumn{4}{|l|}{ Education } \\
\hline Illiterate & $34(17.9 \%)$ & $23(18.1 \%)$ & $36.45(0.000)$ \\
\hline Primary - secondary & $49(25.8 \%)$ & $38(29.9 \%)$ & \\
\hline Middle - intermediate & $83(43.7 \%)$ & $53(41.7 \%)$ & \\
\hline Higher education & $24(12.6 \%)$ & $13(10.3 \%)$ & \\
\hline \multicolumn{4}{|l|}{ Marital status } \\
\hline Married & $186(97.8 \%)$ & $126(99.2 \%)$ & $14.76(0.064)$ \\
\hline Separated & $02(1.1 \%)$ & $00(0.0 \%)$ & \\
\hline Single & $02(1.1 \%)$ & $01(0.8 \%)$ & \\
\hline \multicolumn{4}{|l|}{ Monthly household income } \\
\hline $7000-19,999$ & $42(22.1 \%)$ & $37(29.2 \%)$ & $47.26(0.001)$ \\
\hline $20,000-39,999$ & $38(20.0 \%)$ & $30(23.6 \%)$ & \\
\hline $40,000-59,999$ & $51(26.8 \%)$ & $31(24.4 \%)$ & \\
\hline $60,000-79,999$ & $10(5.3 \%)$ & $06(4.7 \%)$ & \\
\hline $80,000-100,000$ & $26(13.7 \%)$ & $15(11.8 \%)$ & \\
\hline$\geq 100,001$ & $23(12.1 \%)$ & $08(6.3 \%)$ & \\
\hline \multicolumn{4}{|l|}{ Children } \\
\hline None & $07(3.7 \%)$ & $02(1.6 \%))$ & $22.28(0.035)$ \\
\hline $1-3$ & $144(75.8 \%)$ & $95(74.8 \%)$ & \\
\hline $4-6$ & $38(20.0)$ & $29(22.8 \%)$ & \\
\hline 7 or more & $01(0.5 \%)$ & $01(0.8 \%)$ & \\
\hline \multicolumn{4}{|l|}{ Religion } \\
\hline Islam & $181(95.3 \%)$ & $122(96.1 \%)$ & $4.84(0.304)$ \\
\hline Christianity & $09(5.7 \%)$ & $05(3.9 \%)$ & \\
\hline \multicolumn{4}{|l|}{ Current profession } \\
\hline Housewife/Unemployed & $139(73.2 \%)$ & $100(78.7 \%)$ & $14.77(0.044)$ \\
\hline Skilled & $34(17.9 \%)$ & $10(7.9 \%)$ & \\
\hline Unskilled & $17(8.9 \%)$ & $17(13.3 \%)$ & \\
\hline \multicolumn{4}{|l|}{ Type of delivery } \\
\hline Normal vaginal & $62(32.6 \%)$ & $37(29.1 \%)$ & $18.37(0.105)$ \\
\hline Assisted vaginal & $18(9.5 \%)$ & $15(11.8 \%)$ & \\
\hline Emergency $\mathrm{C}$ section & $91(47.9 \%)$ & $63(49.6 \%)$ & \\
\hline Planned C section & $19(10.0 \%)$ & $12(9.5 \%)$ & \\
\hline \multicolumn{4}{|l|}{ Type of institution } \\
\hline Public & $90(47.4 \%)$ & $45(35.4 \%)$ & $36.378(0.000)$ \\
\hline Private & $100(52.6 \%)$ & $82(64.6 \%)$ & \\
\hline \multicolumn{4}{|c|}{ Pre-delivery care services satisfaction } \\
\hline Not satisfied & $46(24.2 \%)$ & $37(26.1 \%)$ & $76.702(0.000)$ \\
\hline Satisfied & $144(75.8 \%)$ & $105(73.9 \%)$ & \\
\hline \multicolumn{4}{|c|}{ Care during delivery satisfaction } \\
\hline Not satisfied & $57(30 \%)$ & $28(19.7 \%)$ & $58.871(0.000)$ \\
\hline Satisfied & $133(70 \%)$ & $114(80.3 \%)$ & \\
\hline \multicolumn{4}{|c|}{ Maternal post-delivery care satisfaction } \\
\hline Not satisfied & $76(40 \%)$ & $42(29.6 \%)$ & $63.012(0.000)$ \\
\hline Satisfied & $114(60 \%)$ & $100(70.4 \%)$ & \\
\hline
\end{tabular}


Table 1 (continued)

\begin{tabular}{llll}
\hline Variable & $\begin{array}{l}f(\%) \\
\mathrm{N}=190\end{array}$ & $\begin{array}{l}\text { Afraid of catching } \\
\text { COVID-19 } \\
\mathrm{n}=142\end{array}$ & $\chi^{2}$ (p-value) \\
\hline Care for newborn satisfaction & & & \\
Not satisfied & $73(38.4 \%)$ & $52(36.6 \%)$ & $60.832(0.000)$ \\
Satisfied & $117(61.6 \%)$ & $90(63.4 \%)$ & \\
\hline
\end{tabular}

\section{Data Analysis}

Initially, descriptive statistics and correlations between study variables were calculated. Next, t-tests were used to identify which socio-demographic characteristics of the participants were significantly associated with fear for self and child catching COVID-19 during institutional delivery. For t-test calculations, socio-demographic variables were recoded into bivariate groups. A final multivariate regression analysis was performed to identify predictors for four maternal and child health support areas of the following: (i) satisfaction with pre-delivery care services; (ii) satisfaction with care during delivery; (iii) satisfaction with maternal post-delivery care; and (iv) satisfaction with care for the newborn.

\section{Results}

\section{Socio-Demographic Characteristics of Sample}

Table 1 presents the socio-demographic characteristics of the sample $(\mathrm{N}=190)$ and the Chi square associations for women who are afraid of catching COVID-19 during institutional deliveries $(n=142,74.7 \%)$. Nearly all of the women are between the ages of 20-39 years (94.2\%) and are married $(97.8 \%)$. A significant number of the women are illiterate $(17.9 \%)$ or have only acquired an education up to tenth grade (25.8\%). A majority of the women have a monthly household income of between PKR 7000-PKR 59,999/USD 42.01-360.06 ${ }^{1}$ (68.9\%) and have between 1-3 children (75.8\%). Nearly all of the women are Muslims (95.3\%) and housewives (73.2\%). A near majority of women had C-sections- emergency or planned, (57.9\%) and had delivered at private hospitals $(52.6 \%)$. The frequencies and percentages of other variables of the study measuring the delivery satisfaction in the women are presented in Appendix B. Most chi square associations for fear of catching COVID-19 show significance and helped determine which variables are included in the multiple regression analysis.

${ }^{1}$ PKR to USD conversions, as at July 15 th 2020 , at the rate of 1 USD to 166.634 PKR, from: https://usd.fxexchangerate.com/pkr/

\section{Mean Analysis for Socio-Demographic Comparisons for Fear Of Catching COVID-19}

The T-test results for differences between mean satisfaction scores, showing greater fear of catching COVID-19 during institutional deliveries, reveal the following: (i) women delivering at public hospitals have greater fear as opposed to those delivering at private hospitals $(M=4.04$ vs. $M=3.10, p=0.000$ ); (ii) illiterate women and women educated up to secondary level (grade 10) have greater fear as opposed to women educated above grade $10(M=3.76$ vs. $M=3.46, p=0.000$ ); (iii) women with $4-7$ children have greater fear as opposed to women with 1-3 children

Table 2 Univariate comparison between socio-demographics and fear of catching COVID-19

\begin{tabular}{|c|c|c|c|}
\hline & $N$ & Mean & $\mathrm{P}$ value \\
\hline \multicolumn{4}{|l|}{ Hospital type } \\
\hline Public & 90 & 4.04 & 0.000 \\
\hline Private & 100 & 3.10 & \\
\hline Education & & & 0.000 \\
\hline Illiterate- secondary & 83 & 3.76 & \\
\hline Intermediate- graduate & 107 & 3.46 & \\
\hline Marital status & & & 0.022 \\
\hline Married & 184 & 3.62 & \\
\hline Separated/widowed & 04 & 2.00 & \\
\hline Monthly household income & & & 0.001 \\
\hline PKR 7000-59,999 & 131 & 3.79 & \\
\hline PKR 60,000-100,000 & 59 & 3.15 & \\
\hline Number of children & & & 0.001 \\
\hline $1-3$ & 151 & 3.49 & \\
\hline $4-7$ & 39 & 4.00 & \\
\hline Religion & & & 0.419 \\
\hline Muslim & 181 & 3.61 & \\
\hline Christian & 09 & 3.22 & \\
\hline Profession & & & 0.001 \\
\hline Unemployed & 139 & 3.76 & \\
\hline Employed & 51 & 3.16 & \\
\hline Type of delivery & & & 0.883 \\
\hline Vaginal & 80 & 3.61 & \\
\hline C-section & 110 & 3.58 & \\
\hline
\end{tabular}


Table 3 Multiple regression model for satisfaction with pre-delivery care services

\begin{tabular}{|c|c|c|c|c|c|c|c|}
\hline \multirow[b]{3}{*}{ Model } & \multicolumn{3}{|c|}{ Coefficients } & \multirow[b]{3}{*}{$\mathrm{t}$} & \multirow[b]{3}{*}{ Sig } & & \\
\hline & \multicolumn{2}{|c|}{$\begin{array}{l}\text { Unstandardized } \\
\text { coefficients }\end{array}$} & \multirow{2}{*}{$\begin{array}{l}\text { Standard- } \\
\text { ized coef- } \\
\text { ficients } \\
\text { B }\end{array}$} & & & \multicolumn{2}{|l|}{$95 \% \mathrm{CI}$ for $\beta$} \\
\hline & $\beta$ & Std. error & & & & Lower bound & Upper bound \\
\hline (Constant) & -0.188 & 0.313 & & -0.601 & 0.549 & -0.805 & 0.429 \\
\hline Hospital type & 0.189 & 0.132 & 0.075 & 1.431 & 0.154 & -0.071 & 0.448 \\
\hline Current profession & 0.173 & 0.075 & 0.108 & 2.303 & 0.022 & 0.025 & 0.321 \\
\hline Fear catching COVID- 19 & -0.124 & 0.045 & -0.140 & -2.743 & 0.007 & 0.035 & 0.213 \\
\hline $\begin{array}{l}\text { Satisfaction with hygiene and sanitation of hospital upon } \\
\text { entry }\end{array}$ & -0.037 & 0.052 & -0.042 & -0.701 & 0.484 & -0.139 & 0.066 \\
\hline Timely registration and room admission & 0.242 & 0.058 & 0.233 & 4.160 & 0.000 & 0.127 & 0.357 \\
\hline Involved in decision-making about your care & 0.265 & 0.056 & 0.254 & 4.705 & 0.000 & 0.154 & 0.376 \\
\hline $\begin{array}{l}\text { Services of hospital staff and administration during pre- } \\
\text { delivery }\end{array}$ & 0.350 & 0.061 & 0.407 & 5.743 & 0.000 & 0.230 & 0.470 \\
\hline
\end{tabular}

Dependent variable: Satisfaction with overall support and attention at hospital for institutional delivery during pre-delivery time

The prediction model was statistically significant, $\mathrm{F}(7,182)=48.480, \mathrm{p}<0.001$

$\mathrm{R} 2=.651$, Adjusted R2 $=.637, *<0.001$

Table 4 Multiple regression model for satisfaction with care during delivery

\begin{tabular}{|c|c|c|c|c|c|c|c|}
\hline \multirow[b]{3}{*}{ Model } & \multicolumn{3}{|c|}{ Coefficients } & \multirow[b]{3}{*}{$\mathrm{t}$} & \multirow[b]{3}{*}{ Sig } & & \\
\hline & $\begin{array}{l}\text { Unstand } \\
\text { coefficie }\end{array}$ & $\begin{array}{l}\text { ardized } \\
\text { nts }\end{array}$ & $\begin{array}{l}\text { Standard- } \\
\text { ized coef- }\end{array}$ & & & \multicolumn{2}{|l|}{$95 \%$ CI for $\beta$} \\
\hline & $\mathrm{B}$ & Std. error & $\mathrm{B}$ & & & Lower bound & Upper bound \\
\hline (Constant) & 0.326 & 0.296 & & 1.102 & 0.272 & -0.258 & 0.910 \\
\hline Education & 0.052 & 0.060 & 0.037 & 0.863 & 0.389 & -0.067 & 0.171 \\
\hline Hospital type & -0.144 & 0.126 & -0.056 & -1.145 & 0.254 & -0.393 & 0.104 \\
\hline Fear catching COVID-19 & -0.012 & 0.042 & -0.013 & -0.295 & 0.768 & -0.095 & 0.070 \\
\hline Satisfaction with hygiene and sanitation of delivery room & 0.070 & 0.048 & 0.080 & 1.459 & 0.146 & -0.025 & 0.166 \\
\hline Comfortable position and movement during delivery & 0.279 & 0.055 & 0.301 & 5.065 & 0.000 & 0.171 & 0.388 \\
\hline Staff assistance in reasonable time during delivery & 0.131 & 0.063 & 0.139 & 2.073 & 0.040 & 0.006 & 0.255 \\
\hline Involved in decision-making during delivery & 0.214 & 0.060 & 0.221 & 3.559 & 0.000 & 0.095 & 0.332 \\
\hline Confidence and trust in staff providing care during delivery & 0.290 & 0.067 & 0.305 & 4.319 & 0.000 & 0.157 & 0.422 \\
\hline
\end{tabular}

Dependent variable: Satisfaction with overall support during delivery

The prediction model was statistically significant, $\mathrm{F}(8,181)=57.005, \mathrm{p}<0.001$

$\mathrm{R} 2=.716$, Adjusted R2 $=.703, *<0.001$

$(M=4.00$ vs. $M=3.49, p=0.001)$; (iv) women having a monthly household income of between PKR 7,000- PKR 59,999/USD 42.01-360.06 have greater fear as opposed to women with income greater than PKR 59,999/ USD 360.06 ( $M=3.79$ vs. $M=3.15, p=0.001)$; (v) unemployed women have greater fear as opposed to those employed $(M=3.76$ vs. $M=3.16, p=0.001)$; and (vi) currently married women have greater fear as opposed to separated or widowed women $(M=3.62$ vs. $M=2.00, p=0.022)$ (Table 2).

\section{Multiple Regression Results for Satisfaction with Delivery Services}

Seven factors explain $65.1 \%$ of the variance in overall satisfaction with pre-delivery care services (Table 3). Five variables show statistical significance in association with satisfaction with overall support and attention during predelivery: (i) services of hospital staff and administration ( $t=5.74, P=0.000)$; (ii) women's involvement in decisionmaking $(t=4.70, P=0.000)$; (iii) timely registration and 
Table 5 Multiple regression model for satisfaction with maternal post-delivery care

\begin{tabular}{|c|c|c|c|c|c|c|c|}
\hline \multirow[b]{3}{*}{ Model } & \multicolumn{3}{|c|}{ Coefficients } & \multirow[b]{3}{*}{$\mathrm{t}$} & \multirow[b]{3}{*}{ Sig } & & \\
\hline & \multicolumn{2}{|c|}{$\begin{array}{l}\text { Unstandardized } \\
\text { coefficients }\end{array}$} & \multirow{2}{*}{$\begin{array}{l}\text { Standardized } \\
\text { coefficients } \\
\text { B }\end{array}$} & & & \multicolumn{2}{|l|}{$95 \%$ CI for $\beta$} \\
\hline & $\beta$ & Std. error & & & & Lower bound & Upper bound \\
\hline (Constant) & 0.569 & 0.373 & & 1.526 & 0.129 & -0.167 & 1.305 \\
\hline Hospital type & 0.505 & 0.182 & 0.177 & 2.767 & 0.006 & 0.145 & 0.865 \\
\hline Current profession & 0.278 & 0.100 & 0.152 & 2.771 & 0.006 & -0.476 & -0.080 \\
\hline Fear catching COVID- 19 & -0.109 & 0.060 & -0.108 & -1.830 & 0.049 & -0.009 & 0.227 \\
\hline Satisfaction with hygiene and sanitation of room or ward & -0.089 & 0.079 & -0.081 & -1.128 & 0.261 & -0.244 & 0.066 \\
\hline $\begin{array}{l}\text { Given all the necessary information and explanations } \\
\text { needed after the birth }\end{array}$ & 0.300 & 0.095 & 0.277 & 3.172 & 0.002 & 0.113 & 0.487 \\
\hline Treated with kindness and understanding after the birth & 0.162 & 0.095 & 0.152 & 1.705 & 0.090 & -0.025 & 0.348 \\
\hline Information about physical recovery after birth & 0.204 & 0.082 & 0.196 & 2.481 & 0.014 & 0.042 & 0.366 \\
\hline
\end{tabular}

Dependent variable: Satisfaction with maternal postnatal care

The prediction model was statistically significant, $\mathrm{F}(7,182)=28.719, \mathrm{p}<0.001$

$\mathrm{R} 2=.525$, Adjusted R2 $=.507, *<0.001$

Table 6 Multiple regression model for satisfaction with care for newborn

\begin{tabular}{|c|c|c|c|c|c|c|c|}
\hline \multirow[b]{3}{*}{ Model } & \multicolumn{3}{|c|}{ Coefficients } & \multirow[b]{3}{*}{$\mathrm{t}$} & \multirow[b]{3}{*}{ Sig } & & \\
\hline & \multicolumn{2}{|c|}{$\begin{array}{l}\text { Unstandardized } \\
\text { coefficients }\end{array}$} & \multirow{2}{*}{$\begin{array}{l}\text { Standardized } \\
\text { coefficients } \\
\text { B }\end{array}$} & & & \multicolumn{2}{|l|}{$95 \%$ CI for $\beta$} \\
\hline & $\beta$ & Std. error & & & & Lower bound & Upper bound \\
\hline (Constant) & 0.169 & 0.200 & & 0.849 & 0.397 & -0.225 & 0.563 \\
\hline Hospital type & -0.083 & 0.128 & -0.030 & -0.649 & 0.517 & -0.337 & 0.170 \\
\hline Fear catching COVID- 19 & 0.030 & 0.041 & 0.030 & 0.744 & 0.458 & -0.050 & 0.110 \\
\hline Satisfaction with hygiene and sanitation of room or ward & 0.100 & 0.050 & 0.093 & 1.988 & 0.048 & 0.001 & 0.200 \\
\hline Advice and support for breast feeding & 0.444 & 0.082 & 0.448 & 5.392 & 0.000 & 0.281 & 0.606 \\
\hline Advice and support for child immunization & 0.268 & 0.081 & 0.269 & 3.297 & 0.001 & 0.108 & 0.429 \\
\hline Advice for emotional changes and attachment with child & 0.019 & 0.059 & 0.020 & 0.317 & 0.752 & -0.098 & 0.136 \\
\hline $\begin{array}{l}\text { Advice for family planning and birth spacing to give } \\
\text { adequate attention to newborn }\end{array}$ & 0.144 & 0.060 & 0.151 & 2.388 & 0.018 & 0.025 & 0.263 \\
\hline
\end{tabular}

Dependent Variable: Satisfaction with care for newborn

The prediction model was statistically significant, $F(7,182)=92.161, p<0.001$

$\mathrm{R} 2=.780$, Adjusted R2 $=.771, *<0.001$

room admission ( $t=4.16, P=0.00)$; (iv) less fear of catching COVID-19 $(t=-2.74, P=0.007)$; and (v) current profession of skilled work ( $t=2.30, P=0.022)$.

Eight factors explain $71.6 \%$ of the variance in overall satisfaction with support during delivery (Table 4). Four variables show statistical significance in association with satisfaction with overall support during delivery: (i) comfortable position and movement ( $t=5.06, P=0.000)$; (ii) confidence and trust in staff $(t=4.32, P=0.000)$; (iii) involved in decision-making $(t=3.55, P=0.000)$; and (iii) staff assistance in reasonable time $(t=2.07, P=0.040)$.

Seven factors explain $52.5 \%$ of the variance in satisfaction with maternal postnatal care (Table 5). Five variables show statistical significance in association with satisfaction with maternal postnatal care: (i) given necessary information and explanations $(t=3.17, P=0.002)$; (ii) private hospital $(t=2.76, P=0.006)$; (iii) working women $(t=2.77$, $P=0.006$ ); (iv) information about physical recovery ( $t=2.48, P=0.014)$; and (v) less fear of catching COVID$19(t=-1.83, P=0.049)$.

Seven factors explain $78.0 \%$ of the variance in satisfaction with care for newborn (Table 6). Four variables show statistical significance in association with satisfaction with care for newborn: (i) advice and support for breast feeding ( $t=5.39, P=0.000$ ); (ii) advice and support for child immunization $(t=3.29, P=0.001)$; (iii) advice for family planning 
and birth spacing ( $t=2.38, P=0.018)$; and (iv) satisfaction with room hygiene and sanitation of room or ward $(t=1.98$, $P=0.048)$.

\section{Discussion}

A majority of our sample indicate a fear of COVID-19 during institutional deliveries in hospitals in Lahore. Recent literature also suggests that vulnerable populations, such as pregnant women, are more at risk of catching COVID19 and, therefore, face great stress and fear on being admitted to hospital for child delivery (Dashraath et al., 2020). On a positive note however, fear has not deterred the respondents from choosing institutional deliveries. Our results suggest that women and their families, coming from urban cities in the developing world, are more cognizant of and committed to safer delivery practices to secure maternal and child health. Our mean analysis results show the significance of specific socio-demographic characteristics with greater fear of catching COVID-19. We find that women from disadvantaged backgrounds suffering illiteracy, unemployment, and low household income have greater fear of contracting COVID-19 during institutional deliveries. International literature suggests that women from more disadvantaged groups face greater risk of infectious diseases (Bishwajit et al., 2014), and also receive less support from healthcare providers during pandemics (McLemore et al., 2018) and national health emergencies (Paz et al., 2020).

Our findings also show that married women with more than four children face greater fear of contracting COVID19. Recent studies from Pakistan also confirm that men and women have greater fear of being infected with COVID-19, as they have more to lose in terms of risk to children and aging parents (Mahmood, 2020). Having already raised children, these women are also more aware of the ramifications of contracting infections on the well-being of children. Our findings further reveal that women delivering at public sector hospitals show greater fear of contracting COVID-19. This finding is not unusual, as most developing countries have poor public sector quality standards, with low levels of delivery satisfaction in women (Peters et al., 2009). Local research confirms that public sector hospitals in the country have unsatisfactory hygiene conditions and quality of care (Kanwal et al., 2017).

With regard to the multiple regression results, our first model showing satisfaction with pre-delivery care services shows significant association with better staff and administration services, greater involvement in decision-making of women, and timely room registrations and admissions. Our findings align with other developing world literature which shows that better hospital services at pre-delivery time improve the satisfaction for women (Sayed et al., 2018). Model 1 also shows that satisfaction with pre-delivery care services is associated with lesser fear of contracting COVID19. The results imply that women are more cognizant of safety protocols for COVID-19 at registration and admission. Hospitals with more visible manifestation for COVID-19 prevention must help to reduce fear in women at the outset, making their stay at hospital a less anxious time. Obvious signs for preventive safety include the following: sterilization at entrance; mandatory face masks; physical distancing in seating areas; frequent sanitation of institution and availability of hand sanitizers; and PPE kits for healthcare staff.

Our second regression model showing satisfaction with care during delivery, shows significant association with comfortable delivery position and movement, confidence and trust in staff, involvement in decision-making, and staff assistance in a reasonable amount of time. Our findings align with developing world literature which suggests that the most pertinent determinants of satisfaction of women in labour is the healthcare provider's interpersonal behaviour in terms of courteousness, promptness, and respect (Srivastava et al., 2015). Our findings also show that during delivery time, the services of healthcare staff are more important for women than the fear of COVID-19. It is possible that a woman, during the delivery period, is more worried about the safe arrival of her child. The implication is that during delivery, women are completely dependent on healthcare staff to ensure hygiene and sanitation.

Our third regression model showing satisfaction with maternal post-delivery care shows significant association with greater provision of necessary information and explanations, relevant to post-care. Our findings corroborate international results that post-delivery satisfaction of women is high when they are provided with adequate information about postnatal care for self and newborn (Karkee et al., 2014). Despite high poverty rates in women in the country and low health financing (Hassan, 2014), of the $66 \%$ of women that do deliver at institutions, $44 \%$ opt to deliver at costly private centers compared to $22 \%$ at free or subsidized public centers (National Institute of Population Studies, 2017-18). Previous research from Pakistan suggests that women are happier with private hospitals compared to public hospitals, due to better services, fewer shortages in staff and resources, and timely service (Ashraf, 2012). Women are also known to face disrespect by staff and providers of public sector hospitals, therefore, influencing their choice for private hospitals (Munawar et al., 2017). Research from other developing regions also corroborates our findings that public sector hospitals are known to provide inferior quality of maternity services in comparison to private sector hospitals (Baltussen $\&$ Ye, 2006). In addition, private sector hospitals perform 
better than public sector hospitals, as they are more patientoriented and maintain a focus on interpersonal relationships between the healthcare provider and patient (Hulton et al., 2007).

Our fourth and final regression model showing satisfaction with care for the newborn shows significant association with greater advice and support for breast feeding, child immunization, family planning and birth spacing. Satisfaction with care for newborn babies also shows satisfaction with room hygiene and sanitation of room or ward. International literature suggests that when women are provided with improved services for newborn feeding, immunization, and birth spacing, it results in improved child development (Bhutta, 2005; Lassi et al., 2014). The findings also reveal that women are more satisfied with the care for newborn post-delivery when the hygiene and sanitation in the room or ward is adequate. Recent research also suggests that women are anxious about hygiene, sanitation and contracting COVID-19 after their infant is born, and before they return home safely (Brooks et al., 2020).

Limitations of this study include the small sample size, perception-based responses, and inability to sample other cities. However, the strength of this study includes the following: (i) gathering data from women across both private and public hospitals; (ii) identifying socio-demographic characteristics of women who are afraid of contracting COVID-19 during institutional deliveries; and (iii) determining factors that are associated with higher satisfaction in delivery services. Our findings can help direct improved policy for hospitals during the age of infectious pandemics. Our study also has implications for other developing regions attempting to improve delivery services at hospitallevel, and also aims to improve institutional delivery rates at national-level. Finally, this study's findings would hold true, not just after the coronavirus pandemic is over, but also when the burden of disease is generally high, as is the case in developing regions of the world, especially Pakistan (Hyder \& Morrow, 2000).

\section{Concluding Recommendations}

Reducing maternal mortality and increasing rates of institutional deliveries has to become a targeted focus if Pakistan is to meet its Sustainable Development Goals. Assessing delivery service satisfaction during the pandemic is valuable research to help allay fears of COVID-19, build trust for institutional deliveries, and improve indicators for maternal and neonatal health even beyond the pandemic. We recommend urgent compliance by the PHC across hospitals and other health delivery centres with regard to: (i) MSDS for maternal and newborn health services; and (ii) preventive protocols for COVID-19. Stricter protocols are especially needed for women population groups defined by low literacy, lower household income, and unemployed status. Availability of standardized services is specifically needed for family planning, child immunization, and breast feeding at both private and public hospitals. To improve accountability in conforming to protocols we recommend that delivery satisfaction surveys of women be linked with hospital licensing, practitioner licensing, and practitioner promotions. Last, special attention needs to be paid to the training of staff and healthcare providers with respect to communications and interpersonal skillset.

Supplementary Information The online version contains supplementary material available at https://doi.org/10.1007/s10995-021-03140-4.

Acknowledgements We thank all the generous respondents for their time and willingness to participate in this study. We also acknowledge our research assistants Mr. Ahmad Faisal Mirza, Ms. Amna Maryum, Ms. Zara Ali Shah, Ms. Sheza Saeed, and Ms. Menahil Shahid for their support in data preparation for transfer from Excel to SPSS. Finally, we must thank Dr. Samia Riaz, Dr. Nadia Seher, Nurse Naseem Bibi, and Nurse Nasreen Fatima for their support in helping us gain relevant permissions.

Author Contributions SRJ has drafted the project, collected the data, analyzed it, and prepared the manuscript. AUM, RW, and AM assisted in data collection. GC reviewed the manuscript. All authors approved the final manuscript.

Funding None.

Data Availability Please note that we have attached the SPSS file with the raw data and the questionnaire as appendix's to the submission.

\section{Declarations}

Conflict of interest The authors declare no conflict of interest.

Ethical Approval Ethics approval for this study was given by the Institutional Review Board of Forman Christian College University.

Informed Consent All participants consented to participate in this study by completing a consent form prior to taking the survey.

\section{References}

Agha, S. (2011). Changes in the proportion of facility-based deliveries and related maternal health services among the poor in rural Jhang, Pakistan: Results from a demand-side financing intervention. International Journal for Equity in Health, 10(1), 57.

Alimohamadi, Y., Khodamoradi, F., Khoramdad, M., Shahbaz, M., \& Esmaeilzadeh, F. (2019). Human development index, maternal mortality rate and under 5 years mortality rate in West and South Asian countries, 1980-2010: An ecological study. Eastern Mediterranean Health Journal= La revue de sante de la Mediterranee orientale $=$ al-Majallah al-sihhiyah li-sharq almutawassit, 25(3), 189-196. 
Ashraf, M., Ashraf, F., Rahman, A., \& Khan, R. (2012). Assessing women's satisfaction level with maternity services: Evidence from Pakistan. International Journal of Collaborative Research on Internal Medicine and Public Health, 4(11).

Baltussen, R., \& Ye, Y. (2006). Quality of care of modern health services as perceived by users and non-users in Burkina Faso. International Journal for Quality in Health Care, 18(1), 30-34.

Bhutta, Z. A., Darmstadt, G. L., Hasan, B. S., \& Haws, R. A. (2005). Community-based interventions for improving perinatal and neonatal health outcomes in developing countries: A review of the evidence. Pediatrics, 115(Supplement 2), 519-617.

Bishwajit, G., Ide, S., \& Ghosh, S. (2014). Social determinants of infectious diseases in South Asia. International Scholarly Research Notices. https://doi.org/10.1155/2014/135243.

Brooks, S. K., Weston, D., \& Greenberg, N. (2020). Psychological impact of infectious disease outbreaks on pregnant women: Rapid evidence review. MedRxiv, 189, 29-36.

Colombara, D. V., Hernández, B., Schaefer, A., Zyznieuski, N., Bryant, M. F., Desai, S. S., \& Palmisano, E. B. (2016). Institutional delivery and satisfaction among indigenous and poor women in Guatemala, Mexico, and Panama. PLoS ONE, 11(4), e0154388.

Dashraath, P., Jeslyn, W. J. L., Karen, L. M. X., Min, L. L., Sarah, L., Biswas, A., \& Lin, S. L. (2020). Coronavirus disease 2019 (COVID-19) pandemic and pregnancy. American Journal of Obstetrics Gynecology, 222(6), 521-531.

de Paz, C., Muller, M., Munoz Boudet, A. M., \& Gaddis, I. (2020). Gender dimensions of the COVID-19 pandemic. In: World Bank.

Habib, A., Black, K. I., Greenow, C. R., Mirani, M., Muhammad, S., Shaheen, F., \& Soofi, S. B. (2019). Evaluation of a maternal, neonatal and child health intervention package in a rural district of Pakistan: A quasi-experimental study. International Journal of Community Medicine Public Health, 6(11), 4682.

Hassan, S. M., \& Ahmad, K. (2014). Globalization: Feminization of poverty and need for gender responsive social protection in Pakistan. Pakistan Vision, 15(2), 58.

Henderson, J., \& Redshaw, M. J. M. (2017). Change over time in women's views and experiences of maternity care in England, 19952014: A comparison using survey data. Midwifery, 44, 35-40.

Hulton, L. A., Matthews, Z., \& Stones, R. W. (2007). Applying a framework for assessing the quality of maternal health services in urban India. Social Science Medicine, 64(10), 2083-2095.

Hyder, A. A., \& Morrow, R. H. (2000). Applying burden of disease methods in developing countries: A case study from Pakistan. American Journal of Public Health, 90(8), 1235.

Jafree, S. R., Zakar, R., Mustafa, M., \& Fischer, F. (2018). Mothers employed in paid work and their predictors for home delivery in Pakistan. BMC Pregnancy and Childbirth, 18(1), 316.

Kanwal, N., Hameed, F., \& Riaz, M. (2017). Assessment and comparison of patients satisfaction with quality of antenatal care services in gynae outpatient department of givernment and private health care settings. Khyber Medical University Journal, 9(1), 1.

Karkee, R., Lee, A. H., \& Pokharel, P. K. (2014). Women's perception of quality of maternity services: A longitudinal survey in Nepal. BMC Pregnancy and Childbirth, 14(1), 45.

Khan, Y. P., Bhutta, S. Z., Munim, S., \& Bhutta, Z. A. (2009). Maternal health and survival in Pakistan: Issues and options. Journal of Obstetrics Gynaecology Canada, 31(10), 920-929.

Khowaja, A. R., Mitton, C., Qureshi, R., Bryan, S., Magee, L. A., von Dadelszen, P., \& Bhutta, Z. A. (2018). A comparison of maternal and newborn health services costs in Sindh Pakistan. PLOS ONE, 13(12), e0208299.

Lancet Neonatal Survival Steering Team. (2005). 4 million neonatal deaths: When? Where? Why? The Journal-Lancet, 365(9462), 891-900.
Lassi, Z. S., Das, J. K., Salam, R. A., \& Bhutta, Z. A. (2014). Evidence from community level inputs to improve quality of care for maternal and newborn health: Interventions and findings. Reproductive Health, 11(S2), S2.

Mahmood, Q. K., Jafree, S. R., \& Qureshi, W. A. (2020). The psychometric validation of FCV19S in urdu and socio-demographic association with fear in the people of the khyber pakhtunkhwa (KPK) province in Pakistan. International Journal of Mental Health and Addiction. https://doi.org/10.1007/s11469-020-00371-4.

Mathole, T., Lindmark, G., Majoko, F., \& Ahlberg, B. M. (2004). A qualitative study of women's perspectives of antenatal care in a rural area of Zimbabwe. Midwifery, 20(2), 122-132.

McLemore, M. R., Altman, M. R., Cooper, N., Williams, S., Rand, L., \& Franck, L. (2018). Health care experiences of pregnant, birthing and postnatal women of color at risk for preterm birth. Social Science Medicine, 201, 127-135.

Mousa, O., \& Turingan, O. M. (2019). Quality of care in the delivery room: Focusing on respectful maternal care practices. Journal of Nursing Education Practice, 9(1), 1-6.

Munawar, A., Hassan, Z. U., Ayub, A., Shaikh, B. T., Buriro, N. A., Ahmed, F., \& Kumar, R. (2017). Women's perceptions about quality of maternity care at tertiary care hospital Karachi, Pakistan. Pakistan Journal of Public Health, 7(2), 109-112.

National Institute of Population Studies. (2013). Pakistan Demographic and Health Survey. In: NIPS and ICF International Islamabad, Pakistan, and Calverton, Maryland, USA.

National Institute of Population Studies. (2017-18). Pakistan Demographic and Health Survey.

Nazir, S. (2015). Determinants of cesarean deliveries in Pakistan. PIDE-Working Papers 2015:122, Pakistan Institute of Economics. Retrieved from https://www.pide.org.pk/pdf/Working\%20Pap er/WorkingPaper-122.pdf.

Peters, D. H., El-Saharty, S., Siadat, B., Janovsky, K., \& Vujicic, M. (2009). Improving health service delivery in developing countries: From evidence to action. The International Bank for Reconstruction and Development / The World Bank. Retrieved from https:// openknowledge.worldbank.org/bitstream/handle/10986/12335/ 48790.pdf; sequence $=1$.

Punjab Healthcare Commission. (2020). Reference Manual- Minimum Service Delivery Standards (MSDS).

Randive, B., San Sebastian, M., De Costa, A., \& Lindholm, L. (2014). Inequalities in institutional delivery uptake and maternal mortality reduction in the context of cash incentive program, Janani Suraksha Yojana: Results from nine states in India. Social Science Medicine, 123, 1-6.

Sarfraz, M., \& Hamid, S. (2014). Challenges in delivery of skilled maternal care-experiences of community midwives in Pakistan. BMC Pregnancy and Childbirth, 14(1), 59.

Sayed, W., AbdElAal, D., Mohammed, H. S., Abbas, A. M., \& Zahran, K. M. (2018). Maternal satisfaction with delivery services at tertiary university hospital in upper Egypt, is it actually satisfying. International Journal of Reproduction Contraception Obstetrics Gynecology, 7(7), 2547-2552.

Simkhada, B., Teijlingen, E. R. V., Porter, M., \& Simkhada, P. (2008). Factors affecting the utilization of antenatal care in developing countries: Systematic review of the literature. Journal of Advanced Nursing, 61(3), 244-260.

Srivastava, A., Avan, B. I., Rajbangshi, P., \& Bhattacharyya, S. (2015). Determinants of women's satisfaction with maternal health care: A review of literature from developing countries. BMC Pregnancy and Childbirth, 15(1), 97.

Tura, G., Fantahun, M., \& Worku, A. (2013). The effect of health facility delivery on neonatal mortality: Systematic review and metaanalysis. BMC Pregnancy and Childbirth, 13(1), 1-9. 
World Health Organization. (2010). Packages of interventions for family planning, safe abortion care, maternal, newborn and child health. Retrieved from https://apps.who.int/iris/bitstream/handle/ 10665/70428/WHO_FCH_10.06_eng.pdf.

Yoseph, M., Abebe, S. M., Mekonnen, F. A., Sisay, M., \& Gonete, K. A. (2020). Institutional delivery services utilization and its determinant factors among women who gave birth in the past 24 months in Southwest Ethiopia. BMC Health Services Research, $20,1-10$.
Publisher's Note Springer Nature remains neutral with regard to jurisdictional claims in published maps and institutional affiliations. 